\section{Australian Journal of \\ Crop Science}

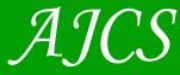

ISSN:1835-2707

AJCS 13(02):251-257 (2019)

doi: 10.21475/ajcs.19.13.02.p1318

\title{
Effects of light quality on rutin production and growth of Physalis angulata (Linn.) seedlings cultured in vitro
}

\author{
Herbert Cristian de Souza ${ }^{1}$, Luís Cláudio Kellner Filho ${ }^{2}$, Marlete Ferreira de Brito ${ }^{3}$, Alessandra Cristina \\ Boffino de Almeida Monteiro Hara ${ }^{3}$, Maria Leonor Beneli Donadon ${ }^{4}$, Rosemeire Cristina Linhari Rodrigues \\ Pietro ${ }^{4}$, Ana Helena Januário ${ }^{2}$, Fabiano Guimarães Silva ${ }^{3 *}$ \\ ${ }^{1}$ Post Graduate Program in Biotechnology and Biodiversity - Pró-Centro-Oeste Network, IPTSP-UFG. 74001-970. \\ Goiânia, Goiás, Brazil \\ ${ }^{2}$ Universidade de Franca (University of Franca - UNIFRAN) - SP. Av. Dr. Armando de Sales Oliveira, 201 - Parque \\ Universitário. 14404-600. Franca, São Paulo, Brazil \\ ${ }^{3}$ Instituto Federal de Educação, Ciência e Tecnologia Goiano (Federal Institute of Education, Science and Technology \\ of Goiás), Rio Verde Campus, Rod. Sul Goiana Km 01, Cx. P. 66. CEP 75.901-970, Rio Verde - Goiás, Brazil \\ "Universidade Estadual Paulista “Júlio de Mesquita Filho" (São Paulo State University - UNESP), Rodovia \\ Araraquara-Jaú - Machados, 14800-901. Araraquara, São Paulo, Brazil
}

*Corresponding author: fabianoifgoiano@gmail.com

Abstract

Physalis angulata Linn. is a plant with great importance in folk medicine for its various therapeutic properties and the production of active compounds. It is known as camapú in Brazil. The $P$. angulata seedlings were cultured in vitro under different light qualities such as white (control), blue, green, red, and yellow at $16 \mathrm{~h}$ photoperiod. After 30 days of culture, the shoot length, number of leaves, fresh and dry matter and rutin content were evaluated in triplicate in methanol extracts of seedlings exposed to the different lights by High-Performance Liquid Chromatography- Diode Array (HPLC-DAD). The mean shoot length was longer in seedlings cultured under yellow light $(22.83 \pm 0.65 \mathrm{~cm}, 1.62$-fold), red light $(22.58 \pm 0.44 \mathrm{~cm}, 1.6$-fold), or green light $(20.57 \pm 0.72$ $\mathrm{cm}, 1.46$-fold) than seedlings exposed to white light $(14.13 \pm 0.26 \mathrm{~cm})$. There were no differences in the mean number of leaves between seedlings grown under the remaining lights and white light. Fresh $(1,152 \pm 0.16 \mathrm{~g})$ and dry weight $(0.078 \pm 0.01 \mathrm{~g})$ were higher in seedlings grown under white light. However, rutin production was higher under blue light $\left(2.78 \pm 0.05 \mu \mathrm{g} \mathrm{g}{ }^{-1}\right.$ by dry weight $)$ and green light $\left(2.40 \pm 0.06 \mu \mathrm{g} \mathrm{g}^{-1}\right.$ by dry weight). Therefore, the various light qualities affected the growth of $P$. angulata seedlings differently under in vitro culture condition. The blue and green lights promoted greater accumulation of rutin in this species.

Keywords: Light quality; Physalis angulata; Tissue culture; Rutin.

Abbreviations: ANOVA_analysis of variance; CV_coefficient of variation; HPLC-DAD_high-performance liquid chromatography diode array; LED_light emitting diode; MS_murashige and skoog; PAR_photosynthetically active radiation; pH_potential of hydrogen; UNESP_são paulo state university; UV_ultraviolet; UV-VIS_ultraviolet-visible spectrophotometry.

\section{Introduction}

Known popularly in Brazil as camapú, Physalis angulata Linn. is a fruit-bearing species of the Solanaceae family with wide ecological adaptation and distribution in tropical and temperate regions of the world (Bastos et al., 2006; AM and Nidavani, 2014). P. angulata is used for medicinal purposes as an analgesic, sedative, antirheumatic, antidiuretic, antiinflammatory, antimalarial, and antiasthmatic, as well as for bladder and prostate problems and liver disorders (Bastos et al., 2006, 2008; Zhang and Tong, 2016). The medicinal effects may be related to the chemical constituents that already characterized in the leaves, which include diterpenes, esters, flavonoids, ceramides, and withasteroids, among others (Tomassini et al., 2000; Zhang and Tong,
2016). The flavonoids are of particular relevance in the genus Physalis due to their antioxidant effects, free radicalscavenging properties, and prevention of degenerative diseases (Pérez-Castorena et al., 2013; Medina-Medrano et al., 2015). Due to its medicinal importance, species of the genus Physalis have been the subject of research in studies on propagation and bioactive compounds (Ramadan, 2011). The culture of Physalis presents some barriers to its commercial production. In vitro tissue culture techniques have shown promise in large-scale production, with the goal of isolating compounds of interest. In tissue culture, it is possible to use elicitors that stimulate plant defense 
mechanisms, promoting metabolism to protect the cell and/or whole plant (Ramirez-Estrada et al., 2016).

Light is considered a fundamental abiotic elicitor for plants. It acts directly and/or indirectly in the growth and development of the plant, promoting modifications in metabolite production (Zavala and Ravetta, 2001; Zoratti et al., 2014). Plants respond specifically to the intensity and quality of light (Wang et al., 2009; Casierra-posada and Peña-olmos, 2015). Thus, it is necessary to optimize the light quality in the spectral range corresponding to the action of different photoreceptors, such as cryptochromes and phototropins. The absorption of light through these photoreceptors induces photomorphogenic responses in plants (Macedo et al., 2011; De Lucas and Prat, 2014; Casierra-posada and Peña-olmos, 2015). Blue light (400-500 $\mathrm{nm})$ and red light $(600-700 \mathrm{~nm})$ promote greater plant growth because the action spectra have maximum absorption at these wavelengths (Li and Kubota, 2009; Hernández and Kubota, 2014).

The use of different light sources at in vitro condition opens up new perspectives for micropropagation and the study of light on explants (Takeui et al., 2017). As an example, the use of blue light may promote higher levels of carotenoids, total polyphenols and antioxidants in Lactuca sativa (Johkan et al., 2010); higher chlorophyll content in Vaccinium myrtillus and Doritaenopsis (Shin et al., 2008; Hung et al., 2016); and increased biosynthesis of flavonoids, flavonoids, flavonols, and jasmonic acid in Picea abies (Ouyang et al., 2015). Pisum sativum irradiated with blue light obtained higher levels of chlorophyll, and those with red light showed higher $\beta$ carotene content and antioxidant activity (Wu et al., 2007). Although some studies show the effects of light quality, works using this tool in plant micropropagation are still scarce, and the effects of light spectrum and irradiance levels on the production of chemical compounds of interest in seedlings grown in vitro are not clear. The objective of this work was to evaluate the influence of light quality on the in vitro growth of $P$. angulata, as well as to quantify the flavonoid rutin in this micropropagated species, aiming to use it in future studies on its production in cell suspension cultures, for commercialization and exploitation of the biotechnological potential of the species.

\section{Results}

\section{Seedling growth and Shoot lengths}

During the 30 days of culture of $P$. angulata seedlings in the different light environments, greater shoot lengths were observed in the seedlings grown under green (1.45-fold), red (1.59-fold), and yellow light (1.61-fold) light compared to white light (control).

On the other hand, the blue light did not alter the growth parameter in comparison to light control.

\section{Number of leaves}

The number of expanded leaves per seedling was not affected by light conditions after 30 days of treatment compared to the control treatment $(6.43 \pm 0.25$ leaves $)$ (Table 1).

\section{Fresh and dry biomass}

Seedlings grown under blue, green, and red light did not differ from each other in accumulation of fresh biomass $(0.932 \pm 1.13 \mathrm{~g}, 0.951 \pm 1.14 \mathrm{~g}$, and $0.998 \pm 1.14 \mathrm{~g}$, respectively) or dry biomass $(0.073 \pm 0.01 \mathrm{~g}, 0.065 \pm 0.01 \mathrm{~g}$, and $0.067 \pm 0.01 \mathrm{~g}$, respectively). However, the weights for these treatments were lower than for the control treatment ( $1.152 \mathrm{~g}$ fresh weight and $0.078 \mathrm{~g}$ dry weight). The treatment of seedlings grown under yellow light had the lowest weights among all the light treatments $(0.803 \pm 1.11 \mathrm{~g}$ fresh weight and $0.053 \pm 0.01 \mathrm{~g}$ dry weight) (Fig. 1).

Analyzing the three growth factors together, it is observed that red, green and yellow lights intensify the shoot lengths compared to white light. However, the blue light was not significantly different to white light used as control. On the other hand, the light quality did not interfere in the number of expanded leaves. Concerning the fresh and dry biomass content, the white light promoted the best production of both biomass content, followed by green and blue red lights, and contrasting with the yellow light that provided the lowest the dry and fresh weights.

\section{Accumulation of the flavonoid rutin}

HPLC-DAD was used to evaluate the rutin content in the samples. After 30 days of culture, the highest accumulation of rutin per flask was observed in seedlings exposed to blue light $\left(2.78 \pm 0.05 \mathrm{\mu g} \mathrm{g}^{-1}\right.$ by dry weight), followed by seedlings cultured under green light $\left(2.40 \pm 0.06 \mu \mathrm{g} \mathrm{g}^{-1}\right.$ by dry weight) and white light $\left(2.23 \pm 0.06 \mu \mathrm{g} \mathrm{g}^{-1}\right.$ by dry weight). Seedlings exposed to red (1.56 $\pm 0.02 \mu \mathrm{g} \mathrm{g}^{-1}$ by dry weight) and yellow light ( $1.66 \pm 0.05 \mu \mathrm{g} \mathrm{g}^{-1}$ by dry weight) had the lowest rutin accumulations. The highest mean rutin yields were found in seedlings grown under blue $(0.2032 \pm 0.004 \mu \mathrm{g})$ and white light $(0.1739 \pm 0.004 \mu \mathrm{g})$. The yields of the seedlings grown under red and yellow light did not differ from the control, with mean values of $0.1045 \pm 0.002 \mu \mathrm{g}$ and $0.0882 \pm 0.003$ $\mu \mathrm{g}$, respectively (Fig. 2).

\section{Discussion}

Light effects can be categorized into photoperiod (duration), intensity (quantity), direction, and quality (wavelength), including UV light (Zoratti et al., 2014).

The light quality regulates the plant growth and development by different mechanisms including the selective activation of light receptors such as phytochrome, cryptochome or phototropin. Thus, different light colors can activate specific plant receptors

In addition, the white light is formed by all other lights, giving it a broader spectrum $(300-750 \mathrm{~nm})$. It is expected that its response in plant growth will be different from example red light, whose more delimited spectral region associated with a narrow bandwidth $(600-700 \mathrm{~nm})$.

In plant tissue culture, the source and the quality of the light directly affect the multiplication and rooting of explants in vitro, since the biological efficiency of the culture media as well as the hormonal balance of the tissues are affected by the light characteristics. In addition, light qualities interfere with the morphogenic and physiological development of seedlings grown in vitro (Vasil and Thorpe, 2003; Neves et al., 2016), affecting shoot length, leaf production, dry weight, root formation, and photosynthetic production, 
Table 1. Mean shoot length and mean number of expanded leaves of $P$. angulata after 30 days of culture in different light treatments.

\begin{tabular}{lcc}
\hline Light Treatment & $\begin{array}{c}\text { Mean shoot } \\
\text { length (cm) }\end{array}$ & $\begin{array}{c}\text { Mean number } \\
\text { of leaves }\end{array}$ \\
\hline White & $14.131 \pm 0.26^{2 \mathrm{~b}}$ & $6.43 \pm 0.25^{\text {a }}$ \\
Blue & $15.44 \pm 0.58^{\mathrm{b}}$ & $6.30 \pm 0.20^{\mathrm{a}}$ \\
Green & $20.57 \pm 0.72^{\mathrm{a}}$ & $6.10 \pm 0.20^{\mathrm{a}}$ \\
Red & $22.58 \pm 0.44^{\mathrm{a}}$ & $6.36 \pm 0.31^{\mathrm{a}}$ \\
Yellow & $22.83 \pm 0.65^{\mathrm{a}}$ & $6.06 \pm 0.28^{{ }^{a}}$ \\
\hline CV (\%) & 8.44 & 9.14 \\
\hline
\end{tabular}
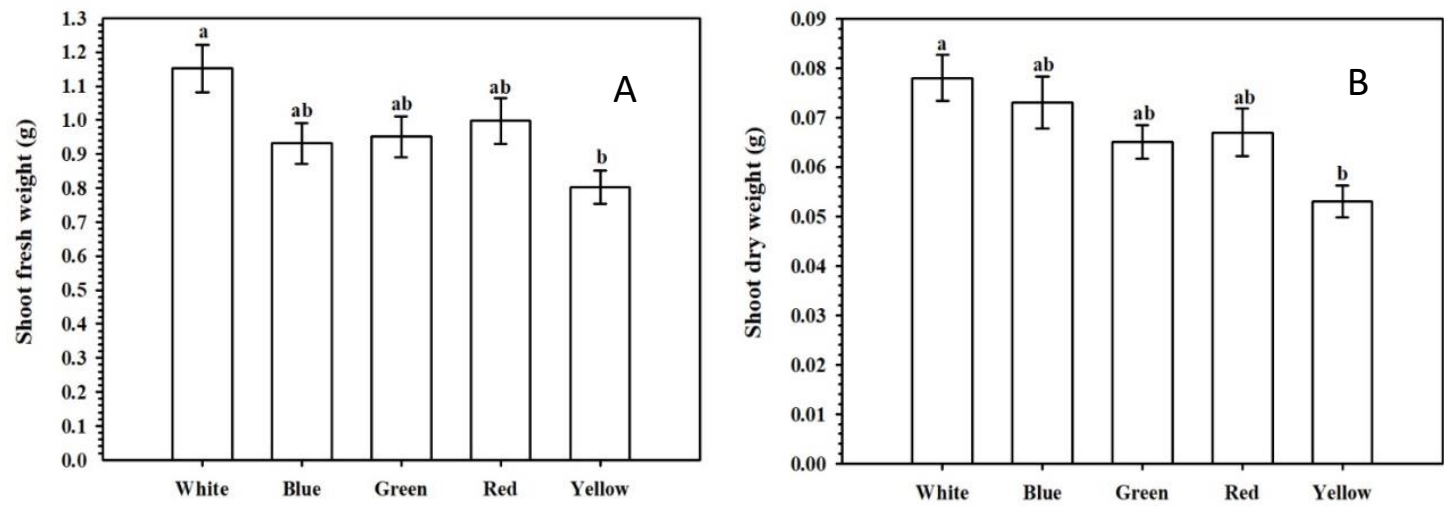

Fig 1. Accumulation of fresh (A) and dry weight (B) in P. angulata seedlings at 30 days of exposure to different light spectra.
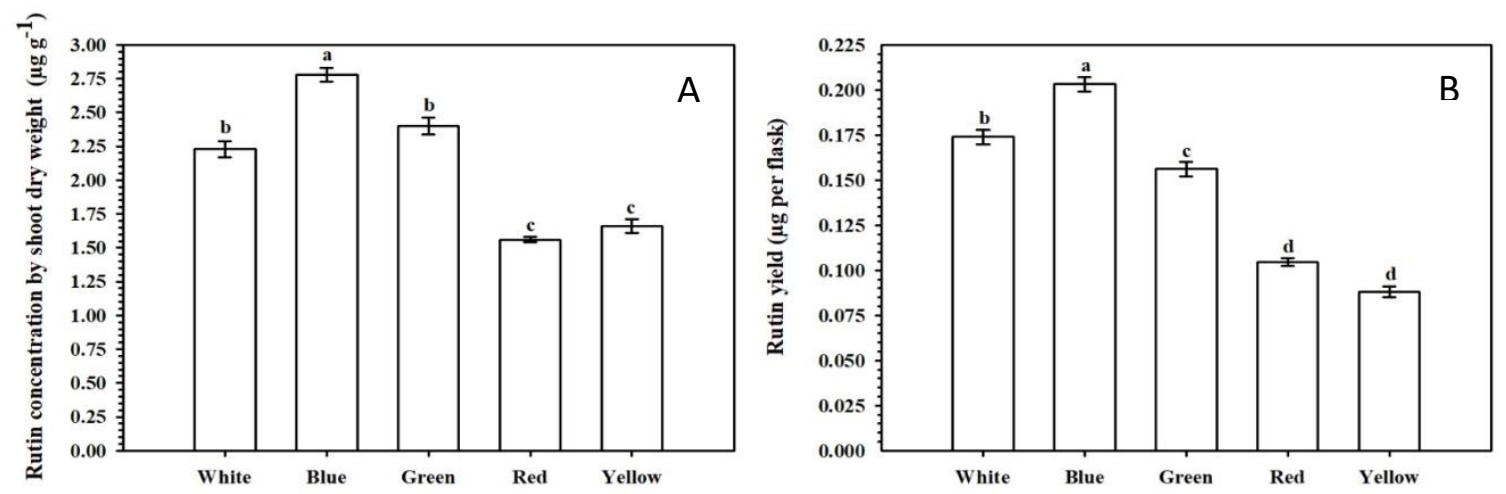

Fig 2. Rutin concentrations and yields ( $A$ and $B$ ) in $P$. angulata seedlings grown under different light qualities. Identical letters indicate no differences according to Tukey's test at a significance level of $5 \%$. Vertical bars represent the standard error of the triplicate mean.

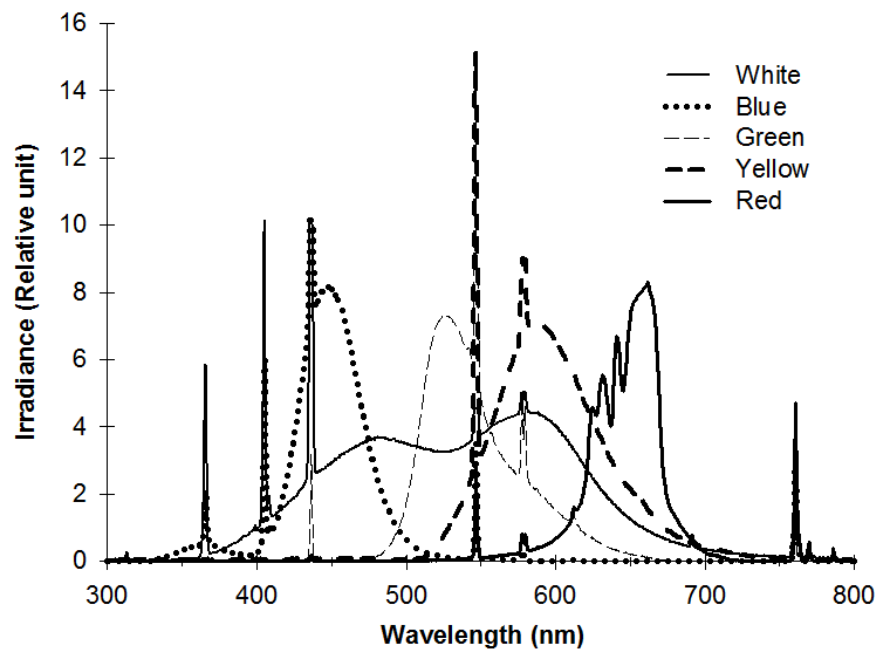

Fig 3. Spectral characteristics of fluorescent lights used in the treatments of $P$. angulata seedlings at 30 days of e xposure to light spectra: white (300-750 nm), blue (400-490 nm), green (490-560 nm), red (600-700 nm), or yellow light (560-590 nm). 
among others (Sæbø et al., 1995; Macedo et al., 2011). In the present work, two independent actions were observed, one dependent on the green, red, and yellow lights, which affected shoot length. The other action depended on the white light, which positively affected the fresh and dry weight, possibly evoking the role of specific photoreceptor systems in the plant response. Our results are in concordance with the studies carried out with Taraxacum japonicum, in which light directly affected the growth of plants under different light qualities, where $100 \%$ rooting was promoted by red light. Moreover, the in vitro cultures irradiated with blue light caused an increase in fresh weight and chlorophyll content (Moon et al., 2006). Regarding the growth parameters such as fresh and dry weight, we found that the maximum increase was obtained for white light, followed by red, green and blue lights. In the same way, the fresh weight, dry weight, and leaf area of Chrysanthemum increased when irradiated with white, red, and blue light at in vitro condition (Kim et al., 2004). Heo et al. (2006) reported that light quality directly affect the in vitro growth of a Vitis sp. variety, since fresh and dry weight and photosynthetic rates were increased when the seedlings were exposed to white, red, or a mixture of blue and red light but were negatively affected only when irradiated with blue light. However, in in vitro cultures of Brassica napus, the proliferation rate was higher in seedlings grown under blue light than under white light (Li et al., 2013). In our study, the number or expanded leaves was not affected by light conditions, contrasting with the case of Anoectochilus formosanus, where green light promoted higher numbers of branches, leaves, and roots when compared to other light qualities (Haque et al., 2016). In addition to inducing changes in morphological and physiological parameters, light quality influenced the concentration and composition of several primary and secondary metabolites (Gobbo-Neto and Lopes, 2007; Zoratti et al., 2014). In this context, if a plant is able to withstand a low-light environment or a deficit in adequate light, that could be a viable alternative to increase the content of secondary metabolites (Hou et al., 2010). Flavonoids and hydroxycinnamic acids are the main phenolic compounds in fruits (He and Giusti, 2010). Such compounds, especially flavonoids and phenylpropanoids, protect against photodamage provided by these metabolites. They absorb and/or dissipate solar energy, preventing UV radiation from damaging more internal tissues (Koyama et al., 2012; Zoratti et al., 2014). Our studies demonstrate that the biosynthesis of the flavonoid rutin was stimulated by blue light and had its smallest contents under the red and yellow lights. The effects of light on the biosynthesis of flavonoids have been reported in several species, where the light intensity and quality influence the growth and accumulation of total flavonoids. In studies with Erigeron breviscapus, biomass and flavonoid production were higher when pants were grown under white film, compared to yellow, red, and purple film (Su et al., 2006). In Vitis sp. treated with LED light emitters, anthocyanin concentrations were highest in the bark treated with blue light, followed by red light treatment (Kondo et al., 2014). In in vitro cultures of Rehmannia glutinosa, blue and red light treatments showed a significant increase in total flavonoid levels in leaf and root extracts (Manivannan et al., 2015). Ghasemzadeh et al. (2010) showed that the synthesis of flavonoids in the Halia Bara variety of Zingiber officinale was improved at lower light intensities. Additionally, in experiments on Ligustrum vulgare leaves, there was a greater accumulation of flavonoids under red light and little accumulation of this metabolite under green light (Tattini et al., 2004). In in vitro cultures of Ruta graveolens, the amount of phenolic acids was stimulated by white and blue lights, whereas the total concentration of furanocoumarins was higher when exposed to blue light. Blue light has been recognized as an important regulator that positively controls the germination, photosynthetic capacity, chlorophyll content, leaf expansion, stem elongation, and height of plants, when compared with white and red light (Sæb $\varnothing$ et al., 1995; Carvalho and Folta, 2014; Takeui et al., 2017). Blue light strongly induces flavonoid production in vitro in species of the genus Alternanthera (Reis et al., 2015), bioflavonoid production in in vitro cultures of Cyclopia subternata calli (Kokotkiewicz et al., 2014), and total flavonoid production in in vitro cultures of Capsicum annuum (Hoffmann et al., 2015). Several species of the genus Physalis are important sources of phenolic compounds with significant antioxidant activity (Tomassini et al., 2000; i̇zli et al., 2014; MedinaMedrano et al., 2015), such as rutin, quercetin, and kaempferol (Sathyadevi and Subramanian, 2015). Rutin has a wide range of therapeutic properties, including antioxidant activity and a role in improving symptoms of lymphatic insufficiency, often associated with circulation problems and bleeding. This flavonoid is found in fruits of Physalis patula Mill., P. solanaceus (Schltdl.) Axelius, P. subulata Rydb (Tomassini et al., 2000), and P. peruviana (Licodiedoff et al., 2013); in the calyx of $P$. solanaceus (Pérez-Castorena et al., 2013); in leaves of P. angulate (Ismail and Alam, 2001); in the shoots of $P$. orizabae (Maldonado et al., 2012); and in in vitro callus cultures of $P$. peruviana (Lashin and Elhaw, 2016). In the present work, the rutin content in $P$. angulata seedlings cultured in vitro show that the light quality directly affected the accumulation of this metabolite. The accumulation of rutin was increased in the presence of blue light and inhibited in the presence of the other light qualities, when compared to the control light. These results indicate that rutin can be used as a specific chemical marker of $P$. angulata and is therefore a relevant indicator of food traceability and drug authenticity. Light quality is an important environmental factor in plant tissue culture in vitro, influencing the development of the plant, in terms of both its morphology and the production of compounds of interest. This study suggests that the light intensity and quality significantly affect in vitro growth as well as rutin accumulation of $P$. angulata seedlings. In addition, the production of high-quality plants of this species with biotechnological potential is possible through in vitro culture, under an adequate mixture of light qualities.

\section{Materials and methods}

\section{Plant material collection and in vitro culture conditions}

The in vitro culture of $P$. angulata was carried out at the Instituto Federal de Educação, Ciência e Tecnologia Goiano (Goiano Federal Institute of Education, Science and Technology) - Rio Verde Campus (GO), and the samples of the plant material were identified by Prof. Dr. Júlio $A$. Lombardi, and deposited in the Herbarium of the Institute of Biosciences of Rio Claro (SP) of the Universidade Estadual Paulista (São Paulo State University, UNESP), under 
accession number 65899. The plant material used was obtained by in vitro germination of seeds of mature fruits collected from seedlings grown in a nursery (geographical location: $17^{\circ} 48^{\prime} 15.9^{\prime \prime} \mathrm{S}, 50^{\circ} 54^{\prime} 22^{\prime \prime} \mathrm{W}, 752 \mathrm{~m}$ altitude). The fruits of $P$. angulata were washed in running water for 20 minutes, then immersed in $70 \%$ alcohol for 30 seconds and placed in a solution of sodium hypochlorite plus water (1:2) for 15 minutes. In a laminar flow cabinet, fruits were washed three to four times with distilled and autoclaved water. With the aid of tweezers and a scalpel, the fruits were cut in half to extract the seeds. The seeds were then placed in flasks with $40 \mathrm{~mL}$ of MS medium (Murashige and Skoog, 1962), containing half of the salt concentration (50\% MS), plus $30 \mathrm{~g}$ $\mathrm{L}^{-1}$ of sucrose and $3.5 \mathrm{~g} \mathrm{~L}^{-1}$ of agar, adjusted to $\mathrm{pH}$ 5.8. The cultures were maintained in a growth room at $25 \pm 2^{\circ} \mathrm{C}$ under daylight-white fluorescence lamps (Taschibra $40 \mathrm{~W}$, Indaial, Santa Catarina, Brazil), with an irradiance of 40 to 55 $\mu \mathrm{mol} \mathrm{m} \mathrm{s}^{-1}$ and a photoperiod of 16 hours.

After 30 days, the seedlings were transplanted using explants of the species originated from in vitro multiplication. For the transplantation, nodal segments approximately $2 \mathrm{~cm}$ long, containing one or two axillary buds, were added to new MS culture medium with the original concentrations, supplemented with $30 \mathrm{~g} \mathrm{~L}^{-1}$ of sucrose, $4.0 \mathrm{~g} \mathrm{~L}^{-1}$ of agar, and $\mathrm{pH}$ adjusted to 5.8. The flasks with $40 \mathrm{~mL}$ of medium were sealed with PVC film. The seedlings were standardized to $2 \mathrm{~cm}$ in length, two expanded leaves, and five seedlings per flask.

\section{Experimental conditions}

The seedlings were subcultured and grown under identical culture conditions for seven days and then transferred to white $(300-750 \mathrm{~nm})$, blue $(400-490 \mathrm{~nm})$, green (490-560 $\mathrm{nm})$, red $(600-700 \mathrm{~nm})$, or yellow light $(560-590 \mathrm{~nm})$ environments, using 40-W Taschibra fluorescent lamps (Indaial, Santa Catarina, Brazil) with an irradiance of $50 \pm 5$ $\mu \mathrm{mol} \mathrm{m} \mathrm{m}^{-1}$ under a photoperiod of $16 \mathrm{~h}$. Spectral quality was determined using al USB2000 spectroradiometer (Ocean Optics, Dunedin, FL, USA) (Fig. 3), and the light intensity was adjusted using a PAR sensor (QSO-S model, Decagon Devices, Pullman, WA, USA). The seedlings were kept under these conditions for 30 days. The light chambers were sealed with a black cloth to prevent light interference.

\section{Biometric analyses}

After 30 days of growth in the light chamber, the plants were evaluated for fresh weight, dry weight, shoot length, and number of leaves per $P$. angulata seedling. After this time, the seedlings were removed from the flasks and immediately weighed to obtain the fresh weight of each one. They were then dried in a forced-air oven at $35^{\circ} \mathrm{C}$ until reaching a constant weight and then weighed to obtain the dry weight.

\section{Quantitative analysis by high-performance liquid chromatography - diode array (HPLC-DAD)}

Rutin accumulation was quantitatively assessed by HPLCDAD in the methanol extracts of seedlings exposed to the different lights. After the dry material had been stored in a dry and cool environment, the chemical analyses were carried out. In this procedure, the dry samples evaluated were prepared using $200 \mathrm{mg}$ of seedlings powder in $5 \mathrm{~mL}$ of HPLC-grade methanol, then extracted for $20 \mathrm{~min}$ in an ultrasonic bath. The samples were analyzed in triplicate.

To obtain the calibration curve, $2 \mathrm{mg}$ of the flavonoid rutin was used as an external standard, and $2000 \mu \mathrm{L}$ of HPLCgrade methanol was added to obtain a stock solution of 1.0 $\mathrm{mg} \mathrm{mL}^{-1}$. Successive dilutions of the stock solution were then performed to obtain the following concentrations: $0.5,0.25$, $0.125,0.0625$, and $0.00625 \mathrm{mg} \mathrm{mL}^{-1}$. Each solution was injected in triplicate into a SHIMADZU Prominence-LC-20AD high-efficiency liquid chromatograph, equipped with an automatic injector (SIL-20A HT), coupled to a UV-VIS model SPD-M20A detector with a diode array. The analytical column used was Phenomenex Phase GEMINI, $(250 \times 4.6$ $\mathrm{mm}, 5 \mu \mathrm{m}), \mathrm{C} 18$, equipped with a pre-column of the same material. The oven was model CTO- $20^{\mathrm{a}}$ which maintained at $40^{\circ} \mathrm{C}$. The volume injected was $20 \mu \mathrm{L}$, and the flow rate was $1 \mathrm{~mL} \mathrm{~min}^{-1}$. The analysis was performed over $60 \mathrm{~min}$ using as eluents in a linear gradient $\mathrm{CH}_{3} \mathrm{OH} / \mathrm{H}_{2} \mathrm{O} / \mathrm{CH}_{3} \mathrm{COOH}$ (5:94, 9:0, $1 \mathrm{v} / \mathrm{v} / \mathrm{v}), 100 \% \mathrm{CH}_{3} \mathrm{OH}$ for $30 \mathrm{~min}, 100 \% \mathrm{MeOH}$ for $10 \mathrm{~min}$, and finally $20 \mathrm{~min}$ to return to the initial condition.

Rutin was quantified based on the peak area at wavelength of $254 \mathrm{~nm}$, using the calibration curve generated, as well as its inherent parameters, namely, the equation of the line $y=$ $42,888,414.5140 x-41,424.6938$ and the linear, angular, and correlation coefficients $\left(R^{2}\right)$, which were obtained using Excel 2016 software. The linearity of the curves obtained between the concentration and the peak area of rutin presented $R^{2}=0.9996$. The flavonoid rutin, used as an external standard, was acquired from the standards bank of the Natural Products Group of the University of Franca (SP).

\section{Experimental design and statistical analysis}

For the growth variables (shoot length and number of leaves) and for the calculation of fresh and dry weight, a completely randomized experimental design was used, which consisted of five treatments, each composed of one type of light and five replicates. Each replicate consisted of one flask with five explants. The numerical data were statistically evaluated using ANOVA followed by Tukey's test (5\%) for comparison of means in SISVAR software (Ferreira, 2011).

\section{Acknowledgements}

Funded by SETEC / MEC and Foundation for Research Support of the State of Goiás (FAPEG).

\section{References}

AM M, Nidavani RB (2014) Physalis Angulata L.: An Ethanopharmacological Review. Indo-American J Pharm Res. 4: 1479-1486.

Bastos GNT, Santos ARS, Ferreira VMM, Costa AMR, Bispo Cl, Silveira AJA, Do Nascimento JLM (2006) Antinociceptive effect of the aqueous extract obtained from roots of Physalis angulata L. on mice. J Ethnopharmacol. 103: 241-245.

Bastos GNT, Silveira AJA, Salgado CG, Picanço-Diniz DLW, do Nascimento JLM (2008) Physalis angulata extract exerts antiinflammatory effects in rats by inhibiting different pathways. J Ethnopharmacol. 118: 246-251. 
Carvalho SD, Folta KM (2014) Sequential light programs shape kale (Brassica napus) sprout appearance and alter metabolic and nutrient content. Hortic Res. 8: 1-13.

Casierra-posada F, Peña-olmos JE (2015) Modificaciones fotomorfogénicas inducidas por la calidad de la luz en plantas cultivadas. Rev Acad Colomb Cienc. 39: 84-92.

De Lucas M, Prat S (2014) PIFs get Bright: phytochrome interacting factors as integrators of light and hormonal signals. New Phytol. 202: 1126-1141.

Ferreira DF (2011) Sisvar: a computer statistical analysis system. Cienc Agrotec. 35: 1039-1042.

Ghasemzadeh A, Jaafar HZE, Rahmat A, Wahab PEM, Halim MRA (2010) Effect of Different Light Intensities on Total Phenolics and Flavonoids Synthesis and Anti-oxidant Activities in Young Ginger Varieties (Zingiber officinale Roscoe). Int J Mol Sci. 11: 3885-3897.

Gobbo-Neto L, Lopes NP (2007) Plantas medicinais: fatores de influência no conteúdo de metabólitos secundários. Quim Nov. 30: 374-381.

Haque SM, Nahar SJ, Shimasaki K (2016) In vitro organogenesis of Anoectochilus formosanaus under different sources of lights. Acta Hortic. 1134: 201-205.

He J, Giusti MM (2010) Anthocyanins: Natural Colorants with Health-Promoting Properties. Annu Rev Food Sci T. 1: 163187.

Heo JW, Shin KS, Kim SK, Paek KY (2006) Light quality affects in vitro growth of grape 'Teleki 5BB'. J Plant Biol. 49: 276-280.

Hernández R, Kubota C (2014) Growth and morphological response of cucumber seedlings to supplemental red and blue photon flux ratios under varied solar daily light integrals. Sci Hortic. 173: 92-99.

Hoffmann AM, Noga G, Hunsche M (2015) High blue light improves acclimation and photosynthetic recovery of pepper plants exposed to UV stress. Environ Exp Bot. 109: 254-263.

Hou J, Li W, Zheng Q, Wang W, Xiao B, Xing D (2010) Effect of low light intensity on growth and accumulation of secondary metabolites in roots of Glycyrrhiza uralensis Fisch. Biochem Syst Ecol. 38: 160-168.

Hung CD, Hong C-H, Kim S-K, Lee K-H, Park J-Y, Nam M-W, Choi D-H, Lee H-I (2016) LED light for in vitro and ex vitro efficient growth of economically important highbush blueberry (Vaccinium corymbosum L.). Acta Physiol Plant. 38: 1-9.

Ismail N, Alam M (2001) A novel cytotoxic flavonoid glycoside from Physalis angulata. Fitoterapia. 72: 676-679.

İzli N, Yıldız G, Ünal H, Işık E, Uylaşer V (2014) Effect of different drying methods on drying characteristics, colour, total phenolic content and antioxidant capacity of Goldenberry (Physalis peruviana L.). Int J Food Sci Tech. 49: 9-17.

Johkan M, Shoji K, Goto F, Hashida S, Yoshihara T (2010) Blue Light-emitting Diode Light Irradiation of Seedlings Improves Seedling Quality and Growth after Transplanting in Red Leaf Lettuce. Hortscience. 45: 1809-1814.

Kim S-J, Hahn E-J, Heo J-W, Paek K-Y (2004) Effects of LEDs on net photosynthetic rate, growth and leaf stomata of chrysanthemum plantlets in vitro. Sci Hortic. 101: 143-151.

Kokotkiewicz A, Bucinski A, Luczkiewicz M (2014) Light and temperature conditions affect bioflavonoid accumulation in callus cultures of Cyclopia subternata Vogel (honeybush). Plant Cell Tiss Org. 118: 589-593.

Kondo S, Tomiyama H, Rodyoung A, Okawa K, Ohara H, Sugaya S, Terahara N, Hirai N (2014) Abscisic acid metabolism and anthocyanin synthesis in grape skin are affected by light emitting diode (LED) irradiation at night. J Plant Physiol. 171: 823-829.

Koyama K, Ikeda H, Poudel PR, Goto-Yamamoto N (2012) Light quality affects flavonoid biosynthesis in young berries of Cabernet Sauvignon grape. Phytochemistry. 78: 54-64.

Lashin II, Elhaw MH (2016) Evaluation of Secondary Metabolites in Callus and Tissues of Physalis peruviana. Int J Mod Bot. 6: 10-17.

Li Q, Kubota C (2009) Effects of supplemental light quality on growth and phytochemicals of baby leaf lettuce. Environ Exp Bot. 67: 59-64.

Li H, Tang C, Xu Z (2013) The effects of different light qualities on rapeseed (Brassica napus L.) plantlet growth and morphogenesis in vitro. Sci Hortic. 150: 117-124.

Licodiedoff S, Koslowski LAD, Ribani RH (2013) Flavonols and antioxidant activity of Physalis peruviana L. fruit at two maturity stages. Acta Sci-Technol. 35: 393-399.

Macedo AF, Leal-Costa MV, Tavares ES, Lage CLS, Esquibel MA (2011) The effect of light quality on leaf production and development of in vitro-cultured plants of Alternanthera brasiliana Kuntze. Environ Exp Bot. 70: 43-50.

Maldonado E, Gutiérrez R, Pérez-Castorena AL, Martínez M (2012) Orizabolide, a New Withanolide from Physalis orizabae. J Mex Chem Soc. 56: 128-130.

Manivannan A, Soundararajan P, Halimah N, Ko CH, Jeong BR (2015) Blue LED light enhances growth, phytochemical contents, and antioxidant enzyme activities of Rehmannia glutinosa cultured in vitro. Hortic Environ Biote. 56: 105113.

Medina-Medrano JR, Almaraz-Abarca N, González-Elizondo MS, Uribe-Soto JN, González-Valdez LS, Herrera-Arrieta Y (2015) Phenolic constituents and antioxidant properties of five wild species of Physalis (Solanaceae). Bot Stud. 56: 2437.

Moon HK, Park S-Y, Kim YW, Kim CS (2006) Growth of Tsururindo (Tripterospermum japonicum) cultured in vitro under various sources of light-emitting diode (LED) irradiation. J Plant Biol. 49: 174-179.

Murashige T, Skoog F (1962) A Revised Medium for Rapid Growth and Bio Assays with Tobacco Tissue Cultures. Physiol Plantarum. 15: 473-497.

Neves CRSS, Procópio MC, Penna TCV (2016) Micropropagation Photoautotrophic Kalanchoe pinnata in Water and Humus with use of Natural Light, and Determination of Total Flavonoids: A Review. Int J Sci Res Sci Technol. 2: 1-13.

Ouyang F, Mao J-F, Wang J, Zhang S, Li Y (2015) Transcriptome Analysis Reveals that Red and Blue Light Regulate Growth and Phytohormone Metabolism in Norway Spruce [Picea abies (L.) Karst.]. Plos One. 10: 1-19.

Pérez-Castorena A-L, Hernández IZ, Martínez M, Maldonado E (2013) Chemical Study of Calyxes and Roots of Physalis solanaceus. Rec Nat Prod. 73: 230-233.

Ramadan MF (2011) Bioactive phytochemicals, nutritional value, and functional properties of cape gooseberry (Physalis peruviana): An overview. Food Res Int. 44: 1830-1836.

Ramirez-Estrada K, Vidal-Limon H, Hidalgo D, Moyano E, Golenioswki M, Cusidó RM, Palazon J (2016) Elicitation, an effective strategy for the biotechnological production of bioactive high-added value compounds in plant cell factories. Molecules. 21: 1-24. 
Reis A, Kleinowski AM, Klein FRS, Telles RT, Do Amarante L, Braga EJB (2015) Light quality on the in vitro growth and production of pigments in the genus Alternanthera. J Crop Sci Biotech. 18: 349-357.

Sæb $\varnothing$ A, Krekling T, Appelgren M (1995) Light quality affects photosynthesis and leaf anatomy of birch plantlets in vitro. Plant Cell Tissue Org. 41: 177-185.

Sathyadevi M, Subramanian S (2015) Extraction, isolation and characterization of bioactive flavonoids from the fruits of Physalis peruviana linn extract. Asian J Pharm Clin Res. 8: 152-157.

Shin KS, Murthy HN, Heo JW, Hahn EJ, Paek KY (2008) The effect of light quality on the growth and development of in vitro cultured Doritaenopsis plants. Acta Physiol Plant. 30: 339-343.

Su W-H, Zhang G-F, Li X-H, Gu F-X, Shi B-L (2006) Effect of light intensity and light quality on growth and total flavonoid accumulation of Erigeron breviscapus. Chin Tradit Herba Drugs. 37: 1244-1252.

Takeui B, Ansante NF, Rossi ML, Calaboni C, Rodrigues PHV (2017) In vitro culture of heliconia in different light sources. Plant Cell Cult Micropropag. 12: 39-45.

Tattini M, Galardi C, Pinelli P, Massai R, Remorini D, Agati G (2004) Differential accumulation of flavonoids and hydroxycinnamates in leaves of Ligustrum vulgare under excess light and drought stress. New Phytol. 163: 547-561.
Tomassini TCB, Barbi NS, Ribeiro IM, Xavier DCD (2000) Gênero Physalis - uma revisão sobre vitaesteróides. Quim Nova. 23: 47-57.

Vasil IK, Thorpe TA (2003) Morphogenesis and Regeneration. In: Thorpe TA (ed) Plant Cell and Tissue Culture, 1 edn. Springer Science \& Business Media, Netherlands, 23. Use the "Insert Citation" button to add citations to this document.

Wang H, Gu M, Cui J, Shi K, Zhou Y, Yu J (2009) Effects of light quality on $\mathrm{CO} 2$ assimilation, chlorophyll-fluorescence quenching, expression of Calvin cycle genes and carbohydrate accumulation in Cucumis sativus. J Photoch Photobio B. 96: 30-37.

Wu MC, Hou CY, Jiang CM, Wang YT, Wang $\mathrm{CY}$, Chen $\mathrm{HH}$, Chang HM (2007) A novel approach of LED light radiation improves the antioxidant activity of pea seedlings. Food Chem. 101: 1753-1758.

Zavala JA, Ravetta DA (2001) Allocation of photoassimilates to biomass, resin and carbohydrates in Grindelia chiloensis as affected by light intensity. Field Crop Res. 69: 143-149.

Zhang W-N, Tong W-Y (2016) Chemical Constituents and Biological Activities of Plants from the Genus Physalis. Chem Biodivers. 13: 48-65.

Zoratti L, Karppinen K, Escobar AL, Jaakola L (2014) Lightcontrolled flavonoid biosynthesis in fruits. Front Plant Sci. 5:1-16. 